\title{
Mikrobiyal gübre uygulamasının karaçam (Pinus nigra Arnold. subsp. pallasiana (Lamb.) Holmboe) fidanlarının bazı morfolojik özelliklerine etkisi
}

Salih PARLAK (Orcid: 0000-0003-3808-3297) ${ }^{1 *}$, Dilek GÜNER (Orcid: 0000-0002-6600-5045)²

\author{
${ }^{1}$ Bursa Teknik Üniversitesi Orman Fakültesi, BURSA \\ ${ }^{2}$ Orman Toprak ve Ekoloji Araştırmaları Enstitüsü Müdürlüğü, ESKİŞEHİR \\ *Sorumlu yazar/Corresponding author: parlaks35@yahoo.com, Geliş Tarihi/Recived: 12.09.2017, Kabul Tarihi /Accepted: 19.09.2017
}

Öz

Ormanlaştırma çalışmaları uzun vadeli ve maliyetli yatırımlardır. Ekolojik koşulların uygunluğundan sonra, bu yatırımların başarısı büyük ölçüde dikilen fidanın kalitesine bağlıdır. Fidan kalite standartlarına uygun olmayan fidanların ağaçlandırma alanlarına dikilmesi, fidan kayıplarının, dolayısıyla tamamlama giderlerinin artmasına neden olmaktadır. Fidanlıklarda kaliteli fidan üretimini etkileyen en önemli faktörler besin, su ve 1ş1k ilișkileridir. Yetersiz veya fazla beslenen fidanlar standart dışı olduğundan tutma başarıları düşmektedir. Bu nedenle, özellikle kurak ve yarı kurak alan ağaçlandırmalarında kullanılacak fidanların, kök/sak oranı dengeli, kök sisteminin çok iyi gelişmiş, suyu ve besini kolayca alabilen yapıda olması istenmektedir. Fidan kalitesini artırmak için orman fidanlıklarında toprak analizi yapıldıktan sonra besin maddesi açığına göre, kimyasal ve organik gübre takviyesi yapılmaktadır. Gübrelerin yarayışlı forma dönüştürülmeleri ve kolay alınabilmelerinde, toprak mikroorganizmalarının fonksiyonu büyüktür. Son yıllarda mineral gübrelemeler yerine, toprak mikroorganizmalarını artırarak besinlerin alınmas1nı sağlayan biyolojik gübreler (biyogübre, bio-inokulant) kullanılmaya başlanmıştır. Özellikle tarımsal ürünlerde verim artış1, hastalıklara karşı direnç, besin maddelerinden daha iyi faydalanma gibi hususlarda başarılı sonuçlar alınmıștır. Biyogübrelerin orman fidanlıklarında kullanımı yeni bir uygulama olup, fidan karakteristiklerine etkileri konusunda Türkiye'de yapılmış bir çalışmaya rastlanılmamıştır. Bu çalışma ile Türkiye'de ormanlaştırılan alanlarda en fazla kullanılan türlerden biri olan karaçamda ekim yastıklarına biyogübre uygulaması yapılarak, bazı fidan morfolojik karakterlerine etkisinin belirlenmesi hedeflenmiştir. Eskişehir Orman Fidanlığında gerçekleştirilen çalışma sonunda, 2+0 yaşlı karaçam fidanlarına uygulanan biyogübrenin, istatistiki bakımdan anlamlı bir fark oluşturmadığ 1 $(P>0,05)$ ortaya konulmuştur.

Anahtar Kelimeler: Biyogübre, Pinus nigra subsp. pallasiana, karaçam, morfolojik özellikler

\section{Effect of microbial fertilizer application on some morphological proper- ties of Pinus nigra Arnold. subsp. pallasiana (Lamb.) Holmboe) seedlings}

\begin{abstract}
Reforestation, afforestation and industrial plantation investments are long term and costly investments. After suitability of ecological conditions, the success of these investments largely depends on the quality of seedlings planted. Planting seedlings that are not in accordance with quality standards causes planting losses, thus the completion costs increase. The most important factors affecting quality seedling production in nurseries are nutrient, water and light relationships. Insufficient or overfed seedlings decline planting success. For this reason, the seedlings to be used for forestation works in especially arid and semi-arid areas are required to be stem/root balanced, and well developed root structures. In order to increase the quality of the seedlings soil analysis is carried out in forest nurseries, chemical and organic fertilizer support are made according to the nutrient deficiency. The function of soil microorganisms is great in converting fertilizers into useful form and easy to take. In recent years, biological fertilizers (bio-fertilizer, bio-inoculant) have started to be used instead of mineral fertilizers to increase soil microorganisms and nutrient available. In particular, successful results have been obtained on the issues such as increased yields, resistance to diseases and better utilization of nutrients in agricultural products. The use of bio-fertilizers in forest nurseries is a new practice and no study has been done on the effects on seedling characteristics in Turkey. The aim of this study is to determine the effects of bio-fertilizers on the morphological characters of some seedlings by applying bio-fertilizer on Crimean pine seedlings which is one of the most used species in the afforestation or reforestation areas in Turkey. At the end of the study conducted in Eskişehir Forest Nursery, it was revealed that the bio-fertilizer applied to $2+0$ Crimean pine seedlings did not make a meaningful difference $(P>0.05)$.
\end{abstract}

Keywords: Bio-fertilizer, Pinus nigra subsp. pallasiana, Crimean pine, morphological characteristics

To cite this article (Atıf): Parlak, S, Güner, D . (2017). Effect of microbial fertilizer application on some morphological properties of Pinus nigra Arnold. subsp. pallasiana (Lamb.) Holmboe) seedlings. Ormancılık Araștırma Dergisi, 4 (2), 100-106.

DOI: http://dx.doi.org/10.17568/ogmoad.337884 


\section{Giriş}

Ülkemizdeki ağaçlandırma faaliyetlerinde kullanılan fidanların tamamına yakını Orman Genel Müdürlüğü’ne ait fidanlıklarda üretilmektedir. Bu fidanlar, ağırlıklı olarak her türlü ormanlaştırma ve rehabilitasyon çalışmalarında kullanılmaktadır. Ormanlaştırma çalışmaları uzun vadeli ve pahalı yatırımlar olduğundan, maliyetlerin mümkün olduğunca düşük tutulması gerekmektedir. Bu nedenle genellikle ekolojik bakımdan sikıntılı alanlar hariç, ekonomik olması sebebiyle ibreli türlerden kızılçam, karaçam, sedir, ladin, sarıçam, göknar ve servi ile bazı yapraklı türler çıplak köklü olarak yetiştirilerek $1+0$ veya $2+0$ yaşlarında ağaçlandırma alanlarına dikilmektedir. Orman Genel Müdürlüğü 2016 yılı faaliyet raporuna göre, orman fidanlıklarında üretilen toplam fidan sayısı 202,5 milyon adet olarak gerçekleşmiştir (Anonim, 2017). Ormanlaştırma faaliyetlerinde kullanılan bu fidanların tutma başarısı ve yaşama yüzdelerinin yüksek olması için fidanlık ortamında mümkün olduğu kadar kaliteli olarak yetiştirilmesi arzu edilmektedir.

Ekolojik koşulların giderek ekstrem şartlara doğru kaydığı ağaçlandırma alanlarına dikilen fidanların, çok daha kaliteli ve kök/sak dengesinin kök lehine olması arzu edilmektedir. Bu suretle, fidanların tutma başarısı ve yaşama yüzdeleri daha yüksek olmakta ve böylece başarılı ormanlaştırmalar yapilabilmektedir. Fidanların kök/sak dengesinin kurulması, fidanlık ortamındaki uygulamalara ve bakımlara bağlı olduğu kadar, toprağın besleme kapasitesi ve yarayışlı besin maddelerinin alınabilirliğine bağlıdır. Topraktaki besin maddelerinin alınabilirliği ise toprağın kolloidal maddelerine ve besinleri indirgeyerek kullanılabilir hale getiren mikroorganizma faaliyetlerinin yoğunluğuna göre değişmektedir. Bu bakımdan topraktaki mikroorganizma faaliyetinin yüksekliği, toprağın verimliliğinin de bir göstergesidir.

Biyolojik gübreler; laboratuvar şartlarında üretilmiş bakterilerin veya köklerle ilişki kuran mikorizal mantarların toprağa doğrudan uygulanmasıdır. Böylece topraktaki besin maddeleri daha etkin olarak kullanılmakta ve fidan kalitesi artmaktadır. Biyogübreler, saçak kök oluşumunu teşvik etmesi nedeniyle (Benitez ve ark., 2004; Contreras-Cornejo ve ark., 2009) fidan tutma ve yaşama oranlarını artırmaktadır. Biyogübrelerin kullanımı sonucunda bitkilerin biyokütlesinde önemli derecede artışların olduğu ispatlanmıştır. Çünkü biyogübreler toprak kaynaklı zararlı patojenleri baskılarken, diğer faydalı bakterilerin etkinliğini artırmaktadır. $\mathrm{Bu}$ durumda, ürün yetiştirmeye engel olan hususlara karşı bitkilerin kök bölgesinde yeni bir mikrobiyal dinamik denge kurulmaktadır (Siddiqui, 2006). Bu gübreler tarım, orman ve süs bitkilerinde uygulama alanı bulmaktadır (Reddy, 2014).
Biyogübreler, bitki için gerekli olan bitki besin maddelerinin sağlanmasında ve biyolojik yolla yarayışlı hale gelmesinde rol oynayan canlı mikroorganizmaların ticari formülasyonlarını ifade etmektedir (Anonim, 2010). Bitki büyümesini teşvik eden mikroorganizmalar, toprağa doğrudan ya da dolaylı olarak ya da tohumun kaplanması şeklinde uygulanarak bitki büyüme potansiyeli olan mikroplar olarak bilinmektedir (Owen ve ark., 2015).

Biyogübreler biyoinokulant, mikrobiyal kültürler, bakteriyel inokulantlar ya da bakteriyel gübreler olarak da isimlendirilir. Biyogübreler faydalarına göre farklı gruplar altında incelenebilir. Fonksiyonlarına göre; azot tespit edenler, fosfatı çözenler, potasyumu çözenler ve sülfürü okside edenler, silikatı çözenler, dekompoze kültürler olarak ayrılabilir. Azot bakterileri ise kendi arasında simbiyotik ve simbiyotik olmayan azot bakterileri şeklinde ayrılir. Azotobacter ve Acetobacter simbiyotik olmayan bakteriler olup havanın serbest azotunu tespit ederler (Borkar, 2015).

Mikroorganizmaların, kimyasal gübreler ve pestisitlerin oluşturduğu problemleri çözmede alternatif olmaları nedeni ile doğal çiftçilik ve organik tarımda kullanılmaları oldukça yaygınlaşmıştır (Berg, 2009). Ormancilıkta kullanımı konusunda yapılan çalışmalar sınırlıdır. Bunlardan en fazla bilineni Rhizobium bakterileri olup, baklagil bitkilerin köklerinde simbiyotik yaşayarak, azot tespit ederler. Aktinomisetler ise orman ağaçlarından kızılağaç, llgın, iğde gibi ağaç ve çalıların köklerinde nodozite meydana getirerek, azot tespitini gerçekleştirir (Anonim, 2010). Literatür taramalarında, orman fidanlıklarında biyogübrenin kullanımı konusundaki çalışmaların birçoğu laboratuvar ortamında yapılmış saksı çalışmalarını içermektedir (Malusá ve ark., 2012). Bu çalışma, orman fidanlarında sahada yapılan ilk çalışma olması sebebiyle önemlidir.

Eskişehir Orman Fidanlığı'nda yürütülen çalışmada $2+0$ yaşlı, yastıkta yetiştirilen çıplak köklü karaçam fidanları kullanılmıştır. Uygulanan biyogübrenin karaçam fidanlarının bazı morfolojik özelliklerine olan etkilerinin belirlenmesi amaçlanmıştır.

\section{Materyal ve Yöntem}

\subsection{Araştırma alanının tanıtımı}

Araştırmada, Denizli Orman Bölge Müdürlüğü, Acıpayam Orman İşletme Müdürlüğü, Elmaözü Şefliği, 109 numaralı bölmede yer alan AcıpayamElmaözü (Alc1) orijinli karaçamla tesis edilmiş olan tohum bahçesinden (TB 141) toplanan tohumlar kullanılmıştır. 141 numaralı tohum bahçesi Denizli İli, Çal İlçesi, Çardak Şefliğii, 54 numaralı bölmede, $37^{\circ} 44^{\prime} 11^{\prime \prime}$ enlem ve $29^{\circ} 44^{\prime} 27^{\prime \prime}$ ' boylamlar1 arasında yer almakta olup, $910 \mathrm{~m}$ yüseltiye sahiptir. 
Çalışmanın fidanlık aşaması $805 \mathrm{~m}$ yükseltide, $39^{\circ}$ 43' $18^{\prime}$ ' $-39^{\circ} 44^{\prime} 48^{\prime}$ " enlemleri ile $30^{\circ} 25^{\prime} 06^{\prime}$ ' $-30^{\circ}$ 26' 43" boylamları arasında bulunan Eskişehir Orman Fidanlığı'nda gerçekleştirilmiştir. Eskişehir, soğuk-yarı karasal iklim tipine sahiptir. Eskişehir meteoroloji istasyonunun 1975-2006 y1llarını kapsayan verilerine göre; yıllık ortalama sıcaklık 10,6 ${ }^{0} \mathrm{C}$, yıllık ortalama yağış miktarı $307,2 \mathrm{~mm}$ dir. Büyüme süresi yaklaşık 240 gündür. Thornthwai- te metoduna göre iklim tipi yarı kuraktır. Sıcaklık ilişkileri bakımından orta sıcaklıklar hâkimdir. Su açığı 305,5 mm olup, haziran-ekim ayları arasındaki beş aylık dönemi kapsamaktadır (Şekil 1). Fidanların yetiştirildiği yastığın 0-30 cm derinlik kademesine ait toprak özellikleri Tablo 1'de verilmiştir. Buna göre denemenin kurulduğu yastık balçıklı kil türündedir.

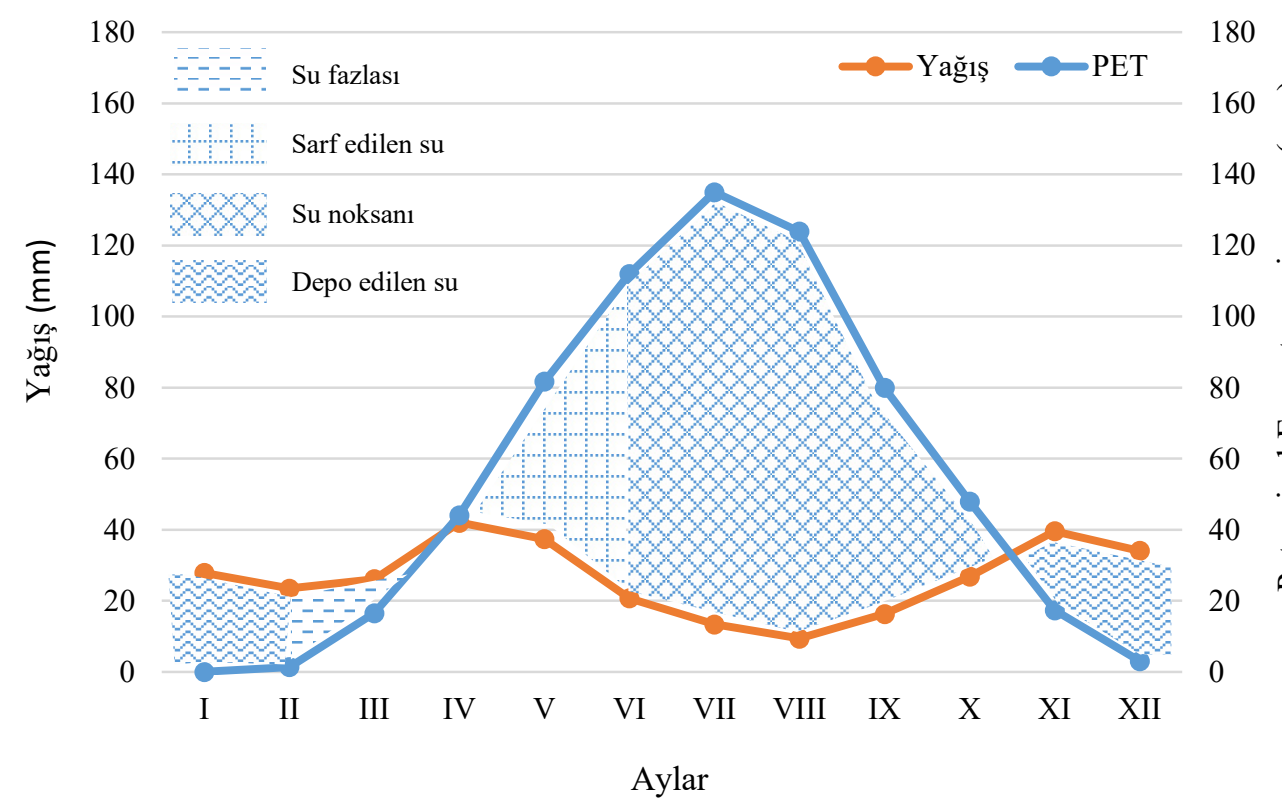

Şekil 1. Thornthwaite yöntemine göre Eskişehir ilinin su bilançosu Figure 1. The Water Balance of Eskişehir According to Thornthwaite Method

Tablo 1. Fidan yastıklarının bazı toprak özellikleri Table 1. Some soil properties of the seedling beds

\begin{tabular}{lclc}
\hline Kum (\%) & 51,7 & Toplam kireç (\%) & 11,61 \\
Toz (\%) & 16,2 & Elektriki iletkenlik (mS/cm) & 0,46 \\
Kil (\%) & 32,1 & Organik madde (\%) & 1,88 \\
Toprak türü & Balçıklı kil & Toplam azot (\%) & 0,10 \\
Toprak reaksiyonu $(\mathrm{pH})$ & 7,70 & $\mathrm{P}_{2} \mathrm{O}_{5}(\mathrm{ppm})$ & 80 \\
\hline
\end{tabular}

\subsection{Denemede kullanılan mikrobiyal gübrenin özellikleri}

Çalışmada kullanılan ve içeriği üretici firma tarafından garanti edilen biyogübrenin içerdiği bakteriler ve etiket verileri Tablo 2'de verilmiştir. Etiket bilgilerine göre biyogübre muhteviyatı mikroorganizmaların toprak pH'sı 4-9 arasında etkin olduğu belirtilmektedir.

Rhizobium, Azotobactor, Azospirilum, Acetobacter türü bakteriler azot tespit eden bakterilerdir. Azotobacter türleri tarımda yaygın olarak kullanılmaktadır. Azotobacter türleri auxin gibi bazı bitki hormanlarını sentezleyerek bitki büyümesini teşvik eder (Borkar, 2015). Azotobacter türleri ile kıyaslandığında, Azospirillum türlerinin 3 kat daha fazla azot tespit ettiği belirlenmiştir. Azospirillum türleri ile inoküle edilen bitkilerin \%15-20 ürün artış1 ve \%20-30 oranında da kimyasal azotu tespit ettiği belirlenmiştir (Borkar, 2015). Toprakta fosfat genelde $\mathrm{pH}$ ve organik maddeye bağlı olarak $\mathrm{Ca}^{2+}$, $\mathrm{Al}, \mathrm{Fe}^{2+}$ ya da $\mathrm{Mn}^{2+}$ ile kompleks formda bulunmaktadır. Ana sorun fosforun toprakta çabuk fikse olması ve nadiren \%10-20 oranına kadar çözülebilmesidir. Kalkerli topraklarda fosfor çözünmez forma dönüştüğünden, bitkiler tarafından alınamaz. 
Pseudomona, Bacillus, Aspergillus ve Penicillium birçok toprak organizması fosforun serbest hale geçmesinde etkilidir. Bunlar, fosfat çözen bakteriler olarak bilinirler (Borkar, 2015).

Tablo 2. Kullanılan biyogübre içeriğ $i$

Table 2. The content of biofertiliser used

\begin{tabular}{l}
\begin{tabular}{l} 
Garanti edilen içerik -Toplam mikroorganizma sayısı: \\
$\qquad \times 10^{7} \mathrm{kob} / \mathrm{ml}$ \\
\hline \multicolumn{1}{c}{ Biyogübre 1} \\
Penicillium bilaii \\
Bacillus megaterium \\
Artrobacter viscosus \\
Azotobacter vinelandii \\
Azotobacter chroococcum \\
Pseudomanas sp. \\
Biyogübrenin özelliği: Havanın serbest azotunu fikse \\
eder, toprakta mevcut bulunan fosfatı çözer, potasyu- \\
mu harekete geçirir.
\end{tabular} \\
\hline
\end{tabular}

\subsection{Fidanlık çalıșmaları}

Denizli Acıpayam-Elmaözü (Alcı) orijinli karaçam tohumları, $120 \mathrm{~cm}$ eninde ve 7 ekim çizgisine sahip (ekim çizgileri arası $15 \mathrm{~cm}$ ) yastıklara, 2015 yılı nisan ayı sonunda ekilmiştir $\left(18 \mathrm{~g} / \mathrm{m}^{2}\right)$. Fidanlara çimlenmeleri takiben ilk yıl fidanlıkta rutin olarak uygulanan gübreleme ve bakım çalışmaları yapılmıştır. 1 yaşını tamamlamış fidan yastıklarından biri seçilerek, 20.06.2016 tarihinde biyogübre denemesi kurulmuştur. Deneme arazide kurulmadan önce, üretici firma tarafından önerilen $1 \mathrm{~m}^{2}$ alana uygulanacak doz $(0,5 \mathrm{ml}$ biyogübre $+10 \mathrm{ml}$ saf su $+0,5$ gr şeker) ile bu dozun 5 katı olacak şekilde ikinci bir doz hazırlanmıştır. Daha sonra hazırlanan karışımlar 24 saat bekletildikten sonra, su ile seyreltilerek süzgeçli kap yardımıyla, ekim yastığında $1 \mathrm{~m}^{2}$ 'lik alanlara uygulanmıştır. Her bir işlem arasında $50 \mathrm{~cm}$ genişliğinde tampon bantlar bırakılmıştır. İşlemlerin yastıklara dağıtımında, "rastlantı parselleri deneme deseni" kullanılmış ve deneme 3 yinelemeli olarak kurulmuştur. Ayrıca, yine tesadüfî olarak belirlenen 3 kontrol parseli de denemeye ilave edilmiştir. Deneme fidanlıkta aplike edildikten sonra, vejetasyon dönemi boyunca rutin ot alma, sulama ve kök kesimi faaliyetlerine devam edilmiştir. Araştırmada yastığın ortasında kalan 5'inci sıradaki fidanlar kullanılmış, yastığın her iki tarafında kenarlara gelen birer sıra fidan tecrit zonu olarak bırakılmıştır.

\subsection{Laboratuvar çalışmaları}

2+0 yaşına gelen fidanlar 20.07.2016 tarihinde rutin bir uygulama olan kök kesimine tabi tutulmuştur. Daha sonra 20.02.2017 tarihinde yapılan kök kesimini takiben fidanlar, yastıktan elle sökülerek, kökler kök boğazından itibaren $30 \mathrm{~cm}$ mesafeden kesilmiştir. Daha sonra laboratuvarda her işlem parselinden rasgele seçilen 20 fidanda fidan boyu (FB), kök boğazı çap1 (KBÇ), sak taze ağırlığ1 (STA), kök taze ağırlığı (KTA), sak kuru ağırlığ1 (SKA) ve kök kuru ağırlığı (KKA) belirlenmiştir. Sak ve kök kuru ağırlık değerleri, fidanlar $70{ }^{\circ} \mathrm{C}$ sıcaklıkta sabit ağırlığa ulaşıncaya kadar (ortalama 48 saat) bekletilerek elde edilmiştir.

\subsection{Değerlendirme}

Veriler istatistik analiz öncesinde normallik denetimine tabi tutulmuş, normal dağılım göstermeyen FB, STA, KTA, FTA, FB/KBÇ ve STA/KTA değerlerine logaritma dönüşümü uygulanmıştır. Kontrol dâhil iki farklı biyogübre dozu uygulamasının 2+0 yaşlı Anadolu karaçamı fidanlarının morfolojik özelliklerine etkisi, her bir özellik bazında ayr1 ayrı varyans analizi ve Duncan testi ile denetlenmiş ve istatistik analizlerde SPSS 22.0 paket programı kullanılmıştır (SPSS v.22.0®, 2015).

Araştırmada $y_{i k}=\mu+\alpha_{i}+\varepsilon_{i k}$ istatistik modeli kullanılmıştır. Modelde, $y_{i k}$ : farklı biyogübre uygulamasına tabi tutulmuş bir fidana ait morfolojik özelliği, $\mu$ : bir fidan özelliğine ait genel ortalama değeri, $\alpha_{i}$ : biyogübrenin etkisini, $\varepsilon_{i k}$ : raslantı hatasını ifade etmektedir.

\section{Bulgular}

Farklı biyogübre uygulamasına tabi tutulmuş $2+0$ yaşlı Anadolu karaçamı fidanlarının morfolojik özellikleri arasındaki farklılıklar Tablo 3 ve Şekil 2'de verilmiştir. Tablo 3 ve Şekil 2 incelendiğinde, farklı biyogübre uygulamasına tabi tutulmuş fidanlar arasında $\mathrm{FB}, \mathrm{KBÇ,} \mathrm{FB} / \mathrm{KBÇ}$ oranı (gürbüzlük indisi), STA, KTA, FTA, SKA, KKA, FKA ve SKA/KKA oranı (katlılık) bakımından anlamlı bir farklılık belirlenememiştir $(P>0,05)$.

\section{Tartışma ve Sonuç}

Biyogübreler canlı mikroorganizmaları ihtiva eden ve kök bölgesinde koloni oluşturan, azot ve fosfor alımını sağlayarak bitki gelişimine katkıda bulunan maddelerdir (Hasrat, 2006). Biyogübrelerle farklı türlerde yapılan fidanlık çalışmalarında; sak ve kök gelişimi, biyokütle ve fidan kalitesi bakımından, kontrole göre artışlar kaydedilmiştir (Deshmukh ve ark., 2007). Biyo-inokulant olarak kullanılan bitki büyümesini teşvik eden mikroorganizmaların, bitkilerde kök sistemlerinin gelişmesini ve ürün miktarını artırdığı bildirilmektedir (Owen ve ark., 2015). Örneğin Azospirillum + AM fungi + Pseudomonas kombinasyonu uygulanan Feronia elephantum (Corr.) fidelerinde kontrole göre, kök uzunluğunun $\% 56,81$, sürgün boyunun $\% 22,72$, kök boğaz çapının \%108,57 ve biyokütlenin \% 77,47 oranında arttığ bildirilmektedir (Deshmukh ve ark., 2007). Erythrina indica fidanlar1 ile yapılan çalışmada, farklı mikrobiyal gübrelerle 
Tablo 3. Farklı biyogübre uygulamasına tabi tutulmuş 2+0 yaşlı Anadolu karaçamı fidanlarının morfolojik özellikleri arasındaki farkl1lıklar $(\mathrm{Ort} \pm \mathrm{SH})$

Table 3. Differences in the morphological characteristics of $2+0$ aged Crimean pine seedlings subject to different bio-fertilisers $($ Mean \pm SE)

\begin{tabular}{|c|c|c|c|c|c|}
\hline \multirow{2}{*}{ Morfolojik özellikler } & \multicolumn{3}{|c|}{ İşlemler } & \multirow{2}{*}{$\begin{array}{c}F \\
\text { Oran1 }\end{array}$} & \multirow{2}{*}{$\begin{array}{c}\text { Önem } \\
\text { Düzeyi }(P)\end{array}$} \\
\hline & Kontrol & İşlem I & İşlem II & & \\
\hline $\mathrm{FB}(\mathrm{cm})$ & $14,56 \pm 0,26 \mathrm{a}$ & $15,30 \pm 0,30 \mathrm{a}$ & $15,44 \pm 0,32 \mathrm{a}$ & 2,399 & 0,094 \\
\hline $\mathrm{KBÇ}(\mathrm{mm})$ & $3,22 \pm 0,06 \mathrm{a}$ & $3,18 \pm 0,06 \mathrm{a}$ & $3,18 \pm 0,07 \mathrm{a}$ & 0,153 & 0,858 \\
\hline FB/KBÇ (GI) & $4,59 \pm 0,10 \mathrm{a}$ & $4,90 \pm 0,13 \mathrm{a}$ & $4,94 \pm 0,12 \mathrm{a}$ & 2,459 & 0,088 \\
\hline STA $(g)$ & $5,39 \pm 0,21 \mathrm{a}$ & $5,40 \pm 0,21 \mathrm{a}$ & $5,84 \pm 0,31$ a & 0,569 & 0,567 \\
\hline KTA $(\mathrm{g})$ & $1,37 \pm 0,05 \mathrm{a}$ & $1,30 \pm 0,05 \mathrm{a}$ & $1,38 \pm 0,07 \mathrm{a}$ & 0,412 & 0,663 \\
\hline FTA (g) & $6,77 \pm 0,26 \mathrm{a}$ & $6,70 \pm 0,25 \mathrm{a}$ & $7,23 \pm 0,38 \mathrm{a}$ & 0,474 & 0,624 \\
\hline SKA (g) & $2,31 \pm 0,11 \mathrm{a}$ & $2,34 \pm 0,11 \mathrm{a}$ & $2,51 \pm 0,09 \mathrm{a}$ & 0,904 & 0,415 \\
\hline KKA (g) & $0,64 \pm 0,03 \mathrm{a}$ & $0,62 \pm 0,02 \mathrm{a}$ & $0,63 \pm 0,02 \mathrm{a}$ & 0,071 & 0,931 \\
\hline FKA $(g)$ & $2,95 \pm 0,14 \mathrm{a}$ & $2,97 \pm 0,14 \mathrm{a}$ & $3,15 \pm 0,12 \mathrm{a}$ & 0,619 & 0,545 \\
\hline SKA/KKA (K) & $3,63 \pm 0,08 \mathrm{a}$ & $3,77 \pm 0,12 \mathrm{a}$ & $3,99 \pm 0,13 \mathrm{a}$ & 2,379 & 0,245 \\
\hline
\end{tabular}

FB: fidan boyu (cm), KBÇ: kök boğazı çapı (mm), Gİ: gürbüzlük indisi, STA: sak taze ağırığı (g), KTA: kök taze ağırlı̆̆ı (g), FTA: fidan taze ağırlığı (g), SKA: sak kuru ağırlığı (g), KKA: kök kuru ağırlığı (g), FKA: fidan kuru ağırlığı (g), K: katlılık, Ort: ortalama, SH: standart hata, $P$ : önem düzeyi, satırlardaki aynı harfler aralarında fark bulunmayan $(P>0,05)$ homojen grupları göstermektedir.
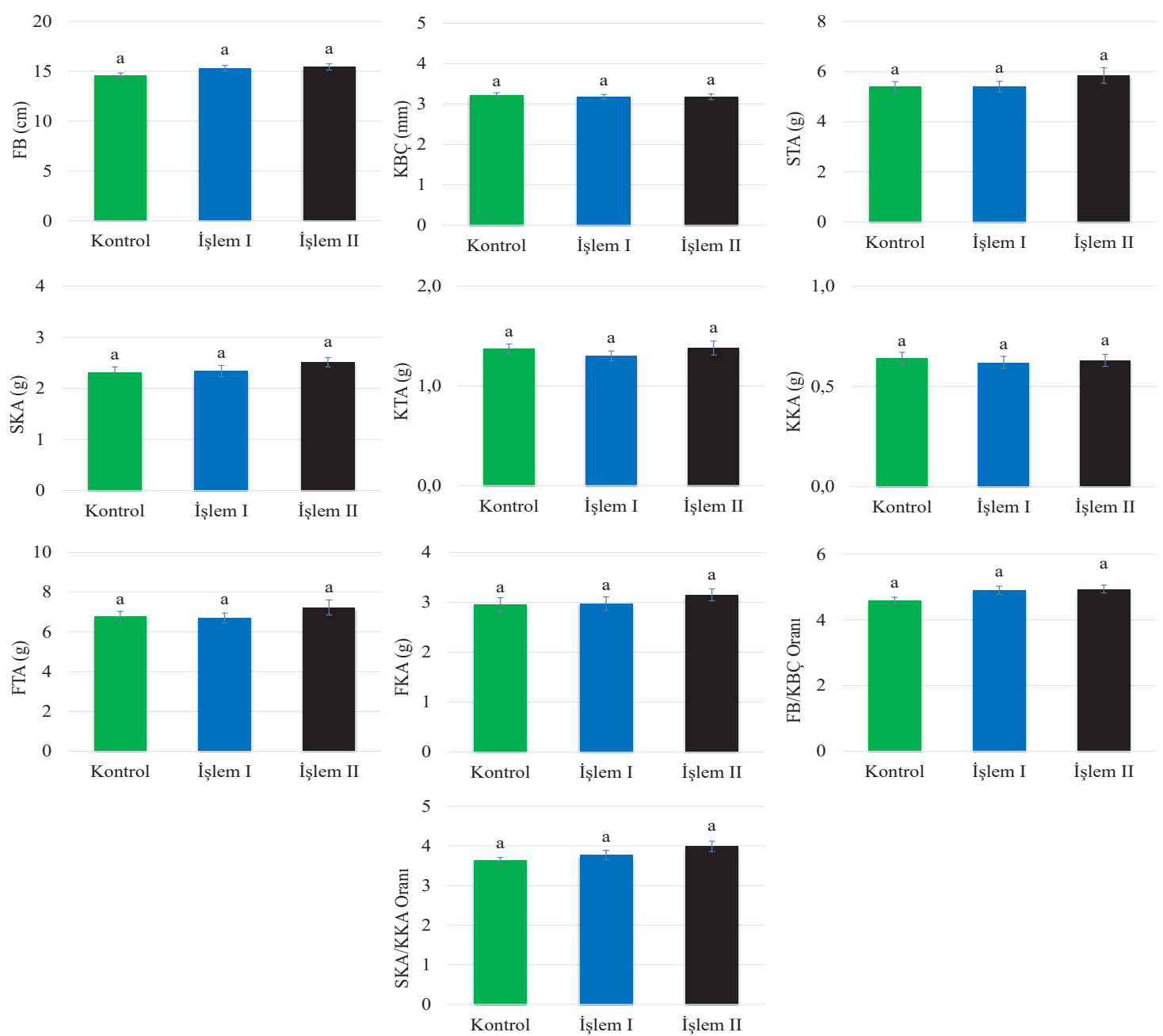

Şekil 2. Farklı biyogübre uygulamasına tabi tutulmuş 2+0 yaşlı Anadolu karaçamı fidanlarının morfolojik özellik ortalamaları ve \pm standart hataları. Her bir morfolojik özellikte aynı harflerle takip edilen ortalamalar $\alpha=0,05$ düzeyinde istatistiki olarak birbirlerinden farklı değildir.

Figure 2. The morphological characteristics of the $2+0$ Crimean pine seedlings subjected to different fertilizer applications and \pm standard errors. The averages followed by the same letters in each morphological feature are not statistically different from each other at $\alpha=0,05$ level. 
bulaşıklık sağlanmış fidanların sürgün ve kök uzunluğu ile kök boğaz çapı bakımından, kontrole göre önemli farklılıklar belirlenmiştir (Kuppurajendran, 2012).

$2+0$ yaşlı çıplak köklü karaçam fidanları ile yaptığımız çalışmada biyogübre, üretici firmanın tavsiye ettiği doz olan $\mathrm{m}^{2}$ 'ye 0,5 gr ve bu dozun 10 katı olacak şekilde 5 gr hazırlanan biyogübre çözeltisi, iki doz şeklinde uygulanmış ve kontrol grubu fidanları ile karşılaştırılmıştır. Fakat uygulanan biyogübre dozlarının, fidanların ölçülen morfolojik karakterleri arasında istatistiki olarak anlamlı bir fark oluşturmadığı belirlenmiştir.

Asif ve ark. (2013)'nın Pinus wallichiana'da yaptıkları çalışmada, farklı biyogübrelerin fidan karakteristiklerine olan etkileri incelenmiş, Azotobacter'in kontrole göre fidan boyunu \%37,17 artırdığ1 belirlenmiștir. Kuppurajendran (2012), Erythrina indica fidanlarında yaptığı çalışmada ise sürgün uzunluğu bakımından Azospirillum ile bulaşık fidanlarda, kontrole göre \%57,71 boy artışı sağlanmıştır. Kök uzunluğu bakımından yine Azospirillum ile bulaşıklık sağlanan fidanlarda, $15,82 \mathrm{~cm}$ ile en yüksek kök uzunluğu elde edilmiş ve kontrole göre \%41,76 artış sağlanmıştır. Melia azedarach L.'da fidanlık ortamında yapılan çalışmada, Glomus geosporum, Azotobacter chroococcum ve Bacillus coagulans kombinasyonu uygulanan fidanların kök ve sürgün boyları ile biyokütle miktarları, kontrole göre daha yüksek gerçekleşmiştir (Rajeshkumar ve ark., 2009). Tectona grandis ile yapılan çalışmada ise Azotobacter uygulanan fidanların gelişimleri nispeten düşük kalmıştır (Paroha ve ark., 2000). Picea glauca (Moench) Voss $\times$ Picea engelmannii Parry ex Engelm.) hibritlerinin tohumlarına yapılan Pseudomonas ve Bacillus uygulaması sürgün ve kök artışını \%10-234 arasında artırmıştır (Shishido ve Chanway, 2000). 2+0 yaşlı karaçamlarda yapt1ğımız çalışmada ise uygulanan biyogübre kombinasyonu fidan boyu bakımından istatistiki olarak anlamlı bir fark meydana getirmemiştir.

Yapılan çalışmalarda uygulanan biyogübrelerin kök boğazı çapını artırdığına dair veriler mevcuttur. Asif ve ark. (2013)'nin çalışmasında, Pseudomonas tinctorius uygulanan fidanlarda \%16,87, Azotobacter uygulananlarda \%13,70, Pseudomonas fluorescens uygulananlarda \%9,81, Bacillus subtilis ise $\% 8,84$ oranında kök boğazı çapını artırdığ1 belirlenmiştir. Kuppurajendran (2012) tarafından Erythrina indica fidanlarında yapılan çalışmada ise kök boğaz çapı bakımından tek doz Azospirillum ile inokule edilen fidanlarda, kontrole göre \%75,54 artış sağlanmıştır. Yaptığımız çalışmada ise karaçam fidanlarında kök boğaz çapı bakımından, uygulanan biyogübre anlamlı bir fark oluşturmamıştır.
Biyokütle bakımından Azospirillum ile inoküle edilen fidanlarda, kontrole göre \%61,55'lik artış sağlanmıştır. Kök kütlesi bakımından da Azospirillum ile yapılan işlem kontrole göre daha yüksek sonuç vermiștir. Toplam biyokütlede ise kontrole göre \%65,23'lik artış sağlanmıştır (Kuppurajendran, 2012). Ilex paraguariensis'in Kosakonia radicincitans ile inokule edildiği çalışmada, sürgün kuru ağırlığının \%183 arttığı belirlenmiştir (Bergottini ve ark., 2015). Eucalyptus camaldulensis ile yapılan çalışmada, uygulanan biyogübre kompozisyonu toplam biyokütle ve büyümeyi artırmıştır (Karthıkeyan ve Suryaprakash, 2008). Fidanlık ortamında Ailanthus excelsa'da yapılan çalışmada, iki biyogübre uygulamasının, bir uygulamadan daha iyi sonuç verdiği bildirilmektedir (Sreedhar ve Mohan, 2016). Azadirachta indica A. Juss fidanlarına iki kez uygulanan Glomus mosseae, Azotobacter chroococcum and Azospirillum brasilense biyogübreleri, kontrole göre, maksimum biyokütle artımını gerçekleştirmiştir (Sumana ve Bagyaraj, 2002). Yaptığımız çalışmada karaçam fidanlarında yaş veya kuru kök ve sak biyokütlesi bakımından uygulanan gübreler anlamlı bir fark oluşturmamıştır. Keza, Borkar (2015), karaçam kontrol fidanlar1 ile biyogübre uygulaması yapılanlar arasında, kök biyokütlesi bakımından önemli bir etkisinin görülmediğini bildirmektedir. Alori ve ark. (2017) uygulanan bazı mikrobiyal inokulantların toprağın mikrobiyallerini artırma veya azaltma yönünde etki edebildiği, bazılarının ise etkisiz olabildiğini ifade etmektedir.

Eskişehir Orman Fidanlığnda yapılan çalışmada, yastıkta yetiştirilen çıplak köklü $2+0$ yaşlı karaçam fidanlarında, ölçülen fidan karakterleri bakımından biyogübre uygulaması anlamlı bir fark oluşturmamıştır. Borkar (2015), biyogübrelerin etkili olabilmesi için optimum sıcaklık isteğinin 20$30{ }^{\circ} \mathrm{C}$ ve $\mathrm{pH}$ 'nın $6,5-7,0$ ve 7,0-7,5 arasında olmas1 gerektiğini bildirmektedir. Denemenin kurulduğu yastıkta toprak sıcaklığı ölçülmemiş ancak, toprak pH's1 7,70 olarak belirlenmiştir. Yapılan çalışmada, biyogübre uygulamasının fidan morfolojik özellikleri üzerinde etkili olmamasının toprak pH'sından kaynaklanmış olabileceği düşünülmekle birlikte, biyogübre uygulamasının tohuma yapılması, ekimi takiben ve $1+0$ yaşından itibaren yapılmasının nasıl sonuçlar vereceği konuları araştırılmalıdır. Biyogübre ile ilgili çalışmalara, farklı fidanlık, tür, yaş ve dozlarda devam edilmelidir.

\section{Kaynaklar}

Alori, E.T., Dare, M, O., Babalola, O.O., 2017. Microbial Inoculants for soil quality and plant health. Sustainable Agriculture Reviews 22: 281-307.

Anonim, 2010. Tarımda kullanılan organik, organomineral gübreler ve toprak düzenleyiciler ile mikrobiyal, 
enzim içerikli ve diğer ürünlerin üretimi, ithalatı ve piyasaya arzına dair yönetmelik. 4 Haziran 2010 tarih ve 27601 sayılı Resmî Gazete.

Anonim, 2017. Orman Genel Müdürlüğü 2016 yılı idare faaliyet raporu, Strateji Geliştirme Dairesi Başkanlığı, Ankara.

Asif, M., Lone, S., Lone, F.A., Hamid, A., 2013. F1eld performance of blue pine (pinus wallichiana) seedlings inoculated with selected species of bio1noculants under nursery conditions. International Journal of Pharma and Bio Sciences 4(1): (B) 632 - 640.

Benitez, T., Rincon, A.M., Limon, M.C., Codon, A.C., 2004. Biocontrol mechanisms of Trichoderma strains. Int. Microbiol. 7: 249-260.

Berg, G., 2009. Plant-microbe interactions promoting plant growth and health: perspectives for controlled use of microorganisms in agriculture. Appl. Microbiol. Biotechnol. 84, 11-18.

Bergottini, V.M., Otegui, M.B., Sosa, D.A., Zapata, P.D., Mulot, M., Rebord, M., Zopfi, J., Wiss, F., Benrey, B., Junier, P., 2015. Bio-inoculation of yerba mate seedlings (Ilex paraguariensis St. Hill.) with native plant growth-promoting rhizobacteria: a sustainable alternative to improve crop yield. Biology and Fertility of Soils 51(6), 749-755.

Borkar, S.G., 2015. Microbes as Biofertilizers and Their Production Technology, Woodhead Publishing India Pvt. Ltd., 218 p.

Contreras-Cornejo, H.A., Macías-Rodríguez, L., CortésPenagos, C., López-Bucio, J., 2009. Trichoderma virens a plant beneficial fungus, enhances biomass production and promotes lateral root growth through an auxin-dependent mechanism in Arabidopsis. Plant Physiol. 49, 1579-1592.

Deshmukh, A.M., Khobragade, R.M., Dixit, P.P.,2007. Handbook of Biofertilizers and Biopesticides. Oxford Book Company 267, 10-B-Scheme, Opp. Narayan Niwas, Gopalpura By Pass Road, Jaipur-302018 ,326 p.

Hasrat, A., 2006. Agro Technology of Organic Farming. Published by: Grassroots Institute c/o Grassroots India Trust 1st Floor, 134, Street 17, Zakir Nagar, Okhla, Opp. New Friends Colony A-Block, New Delhi - 110 025, 21 p.

Karthıkeyan, A., and Suryaprakash, M., 2008. Effects of arbuscular mycorrhizal fung1, Phosphobacterium and Azospirillum Sp.on the successful establishment of Eucalyptus Camaldulensis Dehn. in bauxite mine spoils. Forests and Trees and Livelihoods 18 (2), 183-191.

Kuppurajendran, 2012. Effects of bioinoculants on seed- ling growth, biochemical changes and nutrient uptake of Erythrina 1ndica L. in semi arid region of Southern India. Biometrics \& Biostatistics 3:2, DOI: 10.4172/2155$\underline{6180.1000134 .}$.

Malusá, E., Sas-Paszt, L., Ciesielska, J., 2012. Technologies for beneficial micro-organisms inocula used as biofertilizers. The Scientific World Journal, [Online]. Available: http://www.ncbi.nlm.nih.gov/pmc/articles/ PMC3324119/ doi:10.1100/2012/491206 (accessed on 09.09.17).

Owen, D., Williams, A.P., Griffith, G.W., Withers, P.J.A., 2015. Use of commercial bio-inoculants to increase agricultural production through improved phosphorus acquisition. Applied Soil Ecology 86: 41-54.

Paroha, S., Chandra, K.K., Tiwari, K.P., 2000. Synergistic role of VAM and Azotobacter inoculation on growth and biomass production in forestry species. Journal of Tropical Forestry 16(1): 13-21.

Rajeshkumar, S., Chandran Nisha, M., Chidambaram Prabu P., Wondimu, L., Selvara, T., 2009. Interaction between Glomus geosporum, Azotobacter chroococcum, and Bacillus coagulans and their Influence on growth and nutrition of Melia azedarach L. Turk J Biol 33, 109-114.

Reedy, P.P., 2014. Plant Growth Promoting Rhizobacteria for Horticultural Crop Protection. ISBN 978-81-3221973-6 (eBook), Springer New Delhi Heidelberg New York Dordrecht London, $313 \mathrm{p}$.

Shishido M., and Chanway C.P., 2000. Colonization and growth promotion of out planted spruce seedlings preinoculated with plant growth promoting rhizobacteria in the greenhouse. Can. J. For. Res. 30(6): 845-854.

Siddiqui, Z. A. 2006. PGPR: Prospective biocontrol agents of plant pathogens. In PGPR: Biocontrol and biofertilization, ed. Z. A. Siddiqui, 111-42. Dordrecht, The Netherlands: Springer.

SPSS v.22.0, 2015. SPSS 22.0 Guide to Data Analysis, published by Prentice Hall, Upper Saddle River, New Jersey, USA. 637 pp.

Sreedhar, S.S., and Mohan V., 2016. Effect of different plant growth promoting microbes as bio-Inoculants on the growth improvement of Ailanthus excelsa seedlings in nursery. The Indian Foresters 142 (7),631-641.

Sumana, D.A. and Bagyaraj, D.J. 2002. Interaction between VAM fungus and nitrogen fixing bacteria and their influence on growth and nutrition of neem (Azadirachta indica A. Juss). Indian J. Microbiol. 42(4): 295-298. 